\title{
Clostridia Initiate Heavy Metal Bioremoval in Mixed Sulfidogenic Cultures
}

\author{
Maria Alexandrino,* Rodrigo Costa, Adelino V. M. Canário, and Maria C. Costa \\ Centre of Marine Sciences (CCMar-CIMAR), University of the Algarve, Campus de Gambelas, 8005-139, Faro, Portugal
}

Supporting Information

ABSTRACT: Sulfate reducing bacteria (SRB) are widely used for attenuating heavy metal pollution by means of sulfide generation. Due to their low metal tolerance, several SRB species depend on associated bacteria in mixed cultures to cope with metal-induced stress. Yet the identity of the SRB protecting bacteria is largely unknown. We aimed to identify these associated bacteria and their potential role in two highly metal-resistant mixed SRB cultures by comparing bacterial community composition and SRB activity between these cultures and two sensitive ones. The SRB composition in the resistant and sensitive consortia was similar. However, whereas the SRB in the sensitive cultures were strongly inhibited by a

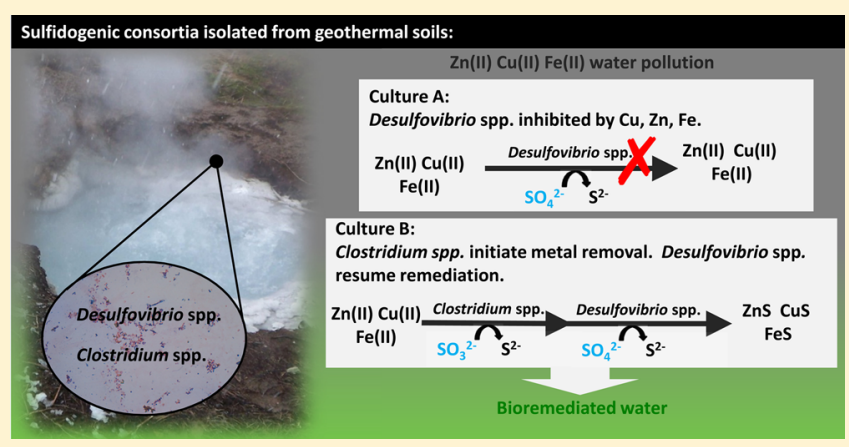
mixture of copper, zinc, and iron, no influence of these metals was detected on SRB growth and activity in the resistant cultures. In the latter, a Gram-positive population mostly assigned to Clostridium spp. initiated heavy metal bioremoval based on sulfide generation from components of the medium (mainly sulfite) but not from sulfate. After metal levels were lowered by the Clostridium spp. populations, SRB started sulfate reduction and raised the $\mathrm{pH}$ of the medium. The combination of sulfite reducing Clostridium spp. with SRB may improve green technologies for removal of heavy metals.

\section{INTRODUCTION}

Large-scale acid mine drainage (AMD) runoffs pose serious environmental and health threats. ${ }^{1-3}$ A promising bioremediation technology to mitigate AMD pollution is based on sulfate reducing bacteria (SRB), as it removes both metals and sulfate, is more economical than the traditional chemical precipitation, and produces less waste., ${ }^{2,4}$ SRB generate sulfide in high amounts, precipitating the heavy metals as sparingly soluble metal sulfides. ${ }^{5}$ SRB usually have moderate tolerance to heavy metals, ${ }^{4,6,7}$ which may be enhanced through mixed cultures. ${ }^{2,7,8}$ Therefore, the use of mixed SRB consortia for AMD remediation is a common practice. However, which and how bacteria in the mixed cultures enhance metal resistance of the SRB populations is still largely unknown. ${ }^{9-12}$

A recent functional screening isolated highly active sulfate reducing cultures from several soils, one of which had sufficient resistance to cope with the heavy metal concentrations present in the Iberian Pyrite Belt AMD, ${ }^{13}$ (9 mM of iron(II), $2.5 \mathrm{mM}$ of zinc(II) and $1.3 \mathrm{mM}$ of copper(II)). ${ }^{14,15}$ Here we aimed to (i) detail the impact of AMD metals on a metal-resistant and two metal-sensitive sulfidogenic cultures, and (ii) identify the bacterial populations and possible mechanisms underlying the metal resistance traits. The results obtained should contribute to improve the current strategies of heavy metal attenuation using natural bacteria.

\section{MATERIALS AND METHODS}

Sample Sources and Mixed SRB Cultures. Mixed SRB cultures were obtained from soils of (a) the bank of the São Domingos stream, Portugal (Mines samples) which receive AMD discharges from an abandoned mine of the same name; (b) the fumarole field in the geothermal area of Hveragerõi, Iceland (Iceland samples); (c) the fumarole field Furnas do Enxofre, a geothermal area on Terceira Island of the Azores Archipelago, Portugal (Furnas samples). Sampling location, $\mathrm{pH}$, and metal content of the soils are described in Table S1 in the Supporting Information (SI). Primary SRB cultures were obtained as described previously ${ }^{13}$ by successive anaerobic $\left(21 \pm 3{ }^{\circ} \mathrm{C}\right)$ inoculations of the soil samples in sealed serum flasks containing Postgate medium $\mathrm{B}^{15}$ supplemented with 0.5 $\mathrm{g} / \mathrm{L} \mathrm{Na}_{2} \mathrm{SO}_{3}$ as reducing agent, ${ }^{16} 0.03 \mathrm{~g} / \mathrm{L}$ of the redox indicator resazurine and $7.8 \mathrm{~g} / \mathrm{L}$ sodium lactate as carbon source (Postgate medium 1). The sediment was discarded after the first inoculation. Growth of SRB was indicated by the formation of a black precipitate of ferrous sulphide, the development of the typical $\mathrm{H}_{2} \mathrm{~S}$ odor, and the decrease of the redox potential to about $-300 \mathrm{mV}$.

Metal Bioremoval Assays. The tolerance of the primary mixed $\mathrm{SRB}$ cultures to $\mathrm{Fe}^{2+}, \mathrm{Cu}^{2+}$, and $\mathrm{Zn}^{2+}$ was tested in 6

Received: November 26, 2013

Revised: February 14, 2014

Accepted: February 25, 2014

Published: February 25, 2014 


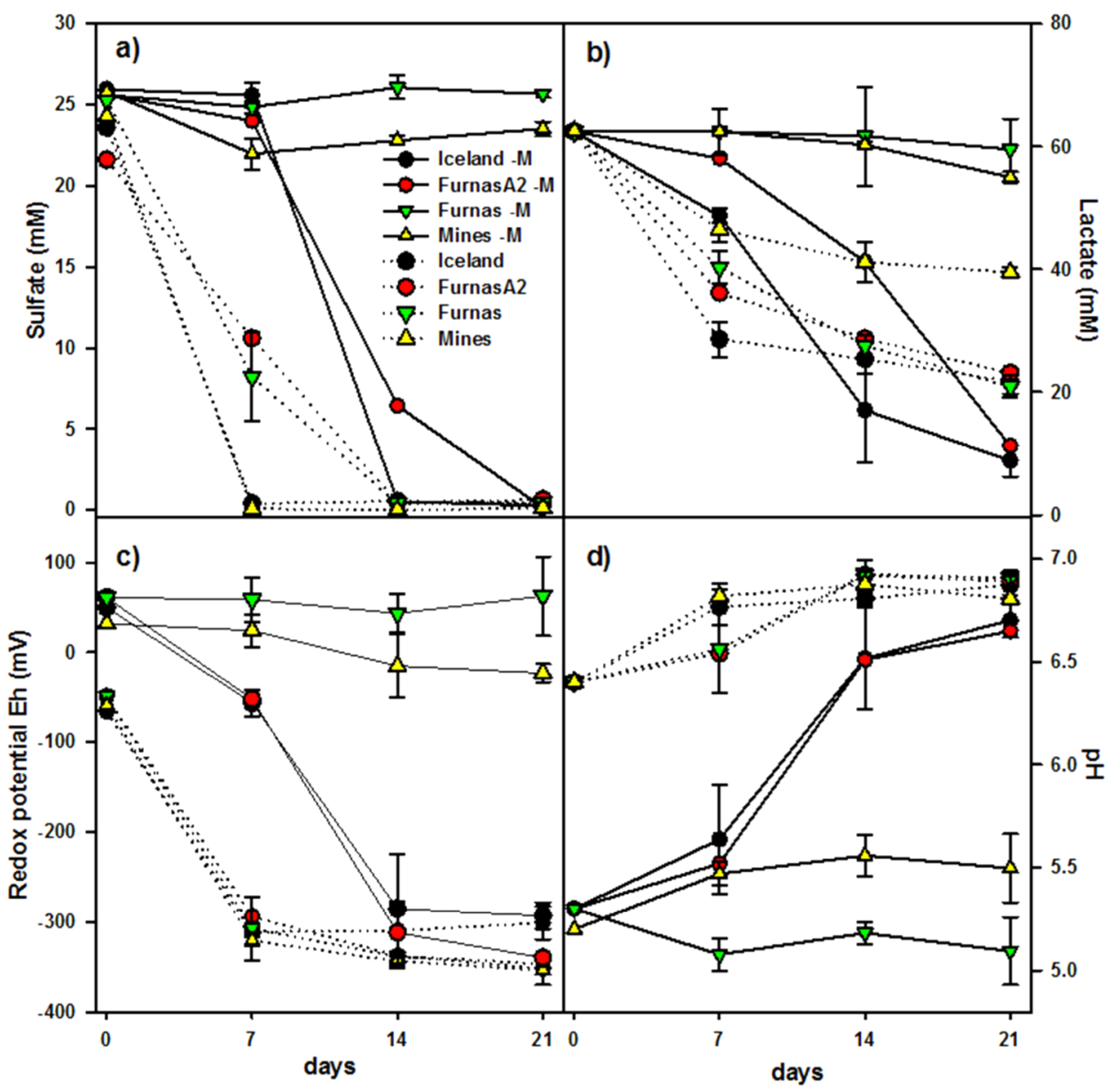

Figure 1. Effect of $\mathrm{Cu}, \mathrm{Zn}$, and $\mathrm{Fe}$ on sulfate reduction (a), lactate consumption (b), redox (c), and $\mathrm{pH}(\mathrm{d})$ variation in the mixed SRB cultures from Iceland, Furnas and Mines. Metal amended cultures $(-\mathrm{M})$ contained $9 \mathrm{mM} \mathrm{Fe}, 2.5 \mathrm{mM} \mathrm{Zn}$, and $1.3 \mathrm{mM} \mathrm{Cu}$. Control cultures were metal-free. Furnas A2 is a single replicate. All other values are means of 5-6 replicates. Error bars indicate standard deviation.

replicates for each sample source and treatment. For the metal treatment group the sulfate salts of iron(II), zinc(II), and copper(II) were added simultaneously to Postgate medium $\mathrm{B}^{15}$ to final concentrations of $9 \mathrm{mM} \mathrm{Fe}(\mathrm{II}), 2.5 \mathrm{mM} \mathrm{Zn}(\mathrm{II})$, and 1.3 $\mathrm{mM} \mathrm{Cu}(\mathrm{II}))$. The $\mathrm{pH}$ of the Postgate medium B decreased from the original 6.4 to 5.3 after metal addition. For each treatment, 6-fold positive controls cultures were carried out without metal addition. Negative controls consisted of noninoculated media. Total sulfate and lactate concentrations of the media were $22-25 \mathrm{mM}$ and $62.5 \mathrm{mM}$, respectively. The cultures were incubated at room temperature $\left(\sim 22{ }^{\circ} \mathrm{C}\right)$. Samples were collected weekly and processed as described below.

Chemical Analysis of the Media. Sulfate and lactate consumption were determined by UV/vis spectrophotometry (Hach-Lange DR2800) using the Sulfa4 method (Hach-Lange) and the SPINREACT Lactate LO-POD Enzymatic colorimetric kit, respectively. Sulfide was measured with the methylene blue method using sulfide reagents 1 and 2 (Hach Lange). Dissolved metals were determined by atomic absorption spectroscopy using a Varian AA-20 model spectrometer. Samples were centrifuged and filtered through a $0.2 \mu \mathrm{m}$ filter prior to re measurements. Redox potential (Eh) and $\mathrm{pH}$ were measured immediately after sample collection using a $\mathrm{pH} / \mathrm{E}$ Meter (GLP 21, Crison).
Bacterial Enumerations and SRB Cultivation. Total bacterial concentrations were determined microscopically after fluorescent staining as described in Alexandrino et al.. ${ }^{13}$ SRB growth was determined by cultivation in Postgate medium $\mathrm{B}^{15}$ amended with $15 \mathrm{~g} / \mathrm{L}$ agar according to the three-tube Most Probable Number method.

Molecular Fingerprinting. After 21 days of incubation, the 12 cultures from each source were subjected to polymerase chain reaction-denaturing gradient gel electrophoresis (PCRDGGE) $16 \mathrm{~S}$ rRNA gene profiling. Whole community DNA extraction, PCR amplification and PCR-DGGE procedures are documented in the SI, along with Figure S1. There was no consistent difference between the dominant PCR-DGGE bands of the metal-amended and the metal-free cultures. Hence, all profile bands were excised, cloned, and sequenced. A phylogenetic tree was constructed with the sequences obtained (Figure S2 in the SI).

Effect of Vancomycin on Metal Resistance. Vancomycin, a macrolide antibiotic that inhibits cell wall synthesis in Gram-positive, but not Gram-negative bacteria, ${ }^{17}$ was used to inactivate the Gram-positive populations of the mixed SRB cultures leaving the SRB (which were Gram-negative) unaffected. Eight replicates of the mixed cultures were inoculated with metals and eight without metals. Vancomycin $(10 \mu \mathrm{g} / \mathrm{mL})$ was added daily to each of four replicates with and without metals. ${ }^{18}$ Negative controls consisted of the non- 


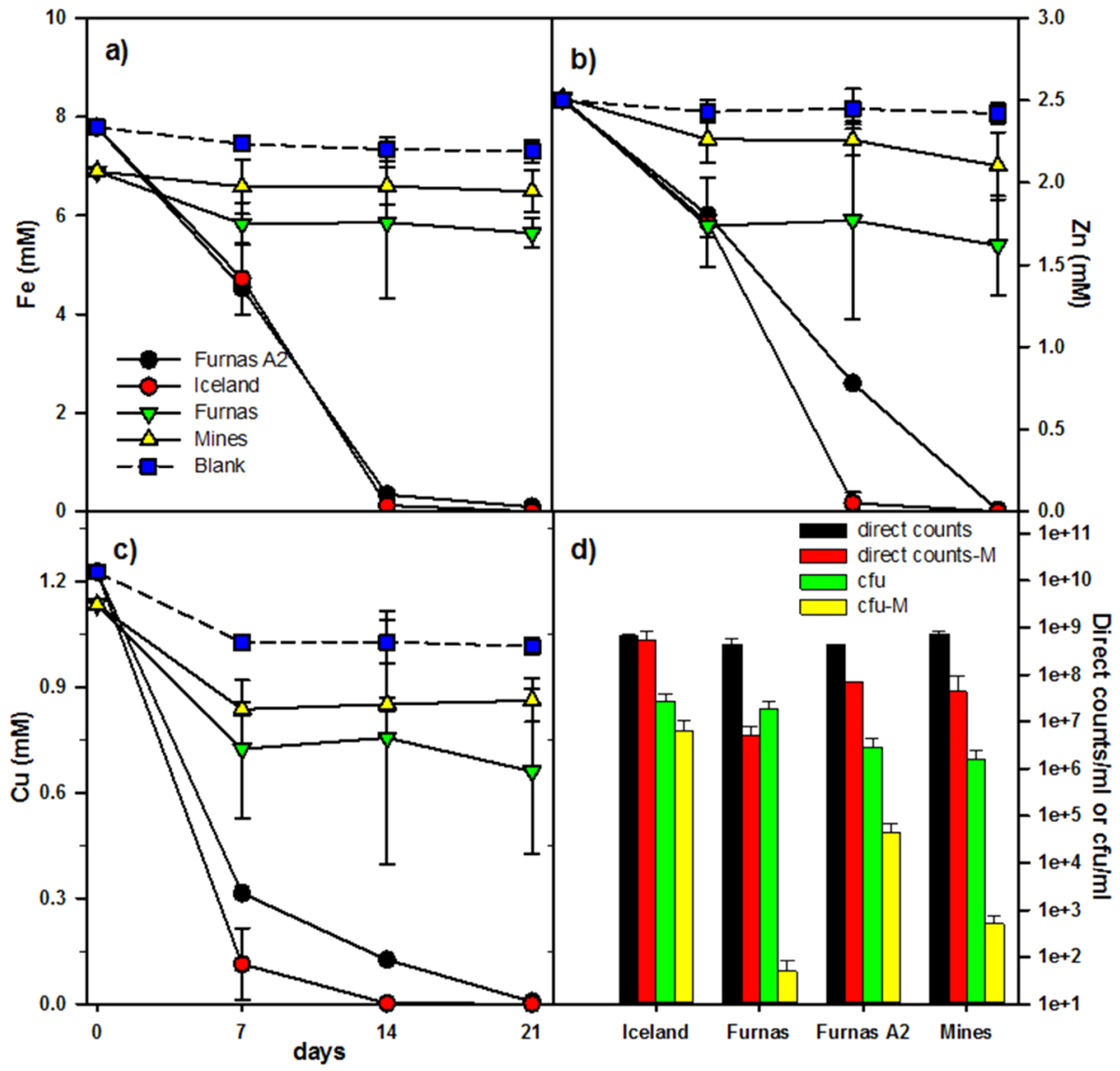

Figure 2. Removal of $\mathrm{Fe}(\mathrm{a}, 9 \mathrm{mM}), \mathrm{Zn}(\mathrm{b}, 2.5 \mathrm{mM})$, and $\mathrm{Cu}(\mathrm{c}, 1.3 \mathrm{mM})$ on the mixed sulfidogenic cultures and concomitant growth of SRB (d, $\mathrm{cfu} / \mathrm{mL}$ ) and of total bacterial cells $(\mathrm{d}$, counts $/ \mathrm{mL})$. Blank: noninoculated media. Direct counts and $\mathrm{cfu} / \mathrm{mL}$ were determined at days 1 and 21 . Furnas A2 is a single replicate. All other values are means of 5-6 replicates. Error bars indicate standard deviation.

inoculated media with the same amendments (replicate cultures with metals, with vancomycin, with both and with none of the amendments).

Isolation of the Clostridia Populations from the Mixed SRB Cultures. After the vamcomycin inactivation test provided strong evidence of the key role of Clostridium spp. on metal resistance of the mixed SRB cultures, this genus was isolated from the rest of the community in order to assess its interaction $\mathrm{s}$ with copper and zinc. Six cycles of successive heating $\left(80^{\circ} \mathrm{C}\right.$, $30 \mathrm{~min})$, inoculation $(0.5 \% \mathrm{v} / \mathrm{v})$, and 7 day incubation were carried out with the mixed SRB cultures in Postgate medium 1 containing $2 \mathrm{~g} / \mathrm{L}$ yeast extract and $4 \mathrm{mM}$ lactate (Postgate medium 2). The lactate concentration was reduced as it mainly serves as a carbon source for SRB. ${ }^{19}$ The absence of SRB was confirmed by PCR targeting the gene coding for the enzyme bisulfite reductase $(d s r a b)^{20}$ on 2 ng DNA extracted from cultures $(5 \mathrm{~mL})$ with the Ultraclean Soil DNA Isolation Kit (Mo BIO Laboratories Inc.) A control PCR was carried out with the primers BAC-8F/BAC-1492 $\mathrm{R}^{21}$ to avoid false negatives. Finally, the identity of the isolated bacteria was confirmed by cloning the amplified 16S rRNA gene fragments (primers BAC-8F/BAC-1492R) ${ }^{21}$ from the extracted DNA as described below for the mixed SRB cultures. For each source, 20 colonies were randomly picked and sequenced as described below.

Metal Bioremoval by Clostridium spp. The tolerance of the isolated Clostridium spp. to $\mathrm{Zn}$ and $\mathrm{Cu}$ and their metalbioremoval capacity was assessed in three independent assays with duplicate cultures. Modified Postgate medium B (medium 2) was supplemented with $1 \mathrm{mM} \mathrm{Cu(II),} 1 \mathrm{mM} \mathrm{Zn(II),} \mathrm{or} 2.5$ $\mathrm{mM} \mathrm{Zn(II)}$ or mixtures of $1 \mathrm{mM}$ copper $+1 \mathrm{mM} \mathrm{Zn(II)} \mathrm{or} 1$ $\mathrm{mM} \mathrm{Cu}(\mathrm{II})+2.5 \mathrm{mM} \mathrm{Zn}(\mathrm{II})$. All cultures contained $1.5 \mathrm{mM}$ iron(II), a component of the Postgate medium B. Metal bioremoval was determined for living cells, for their cell-free supernatants, and for dead (autoclaved, $121{ }^{\circ} \mathrm{C}, 30 \mathrm{~min}$ ) cultures. Clostridium-free supernatant was obtained by filtering the cultures after three days of incubation. The total sulfate and lactate concentrations of the media were $15-16 \mathrm{mM}$ and 4 $\mathrm{mM}$, respectively. All cultures were inoculated and incubated anaerobically in sealed serum flasks and samples were collected weekly and processed as described below.

\section{RESULTS}

Effect of Heavy Metals on SRB in Mixed Cultures. All SRB cultures incubated without metals had high metabolic activity: the sulfate in solution was depleted in the first week (Figure 1a); lactate was consumed extensively (20-40 mM, Figure 1b); the redox potential decreased in 7 days from between -50 and $-60 \mathrm{mV}$ to between -300 and $-350 \mathrm{mV}$ (Figure 1c) and $\mathrm{pH}$ increased from 6.4 to 6.8 (Figure 1d).

Metal addition and the concomitant $\mathrm{pH}$ decrease almost completely inhibited metabolic activity in the Mines and Furnas (with the exception of replicate Furnas A2); the initial redox potential and $\mathrm{pH}$ of the culture medium $(50-60 \mathrm{mV}$ and 5.4, Figure 1c,d) remained unchanged. No sulfate reduction was detected (Figure 1a) and only 11\% (Furnas) and 5\% (Mines) 
of the lactate was consumed (Figure 1b). Interestingly, similar to the Iceland samples, the Furnas A2 replicate displayed metabolic activity in the presence of the tested metals, as well (Figure 1a to 1d). Therefore, the results obtained for this culture were always processed separately from the other Furnas samples. In the presence of metals, the Iceland and Furnas A2 cultures fully resumed sulfate reduction after a lag of at least 7 days (Figure 1a). Lactate consumption was low during the first 7 days but, in the following 14 days, it was higher in the metalamended Iceland and Furnas A2 cultures than in the corresponding metal-free controls (Figure 1b). The redox potential in these cultures decreased less after 7 days than the metal-free controls, but decreased sharply during the following 7 days to $-300 \mathrm{mV}$ (Figure 1c). The $\mathrm{pH}$ followed a similar pattern, starting at 5.4, lower than in the metal-free cultures, and increasing to 6.7 after sulfate reduction started (Figure 1d). Metals remained in solution after 21 days in the metal-sensitive cultures (Figure $2 \mathrm{a}-\mathrm{c}$ ), whereas over $99 \%$ was removed in the Iceland and Furnas A2 cultures over the same period. In these cultures, metal concentrations decreased considerably during the first week, despite no sulfate reduction being detected (Figure $2 \mathrm{a}-\mathrm{c}$ ): $\mathrm{Fe}$ concentration decreased by $39.4 \%$ and 41.8\%; $\mathrm{Zn}$ by $29.6 \%$ and $27.8 \%$; and $\mathrm{Cu}$ by $90.8 \%$ and $74.4 \%$.

Effect of Heavy Metals on Cell Growth. The tested metals (and possibly the lower $\mathrm{pH}$ of the culture medium due to metal amendment) had a strong negative impact on the recovery of culturable SRB from the metal-sensitive cultures (Figure 2d): SRB concentrations in the Mines and Furnas samples decreased almost 4 and 6 orders of magnitude, respectively, than their respective metal-free cultures. Recovery of SRB after metal exposure in the metal-resistant Iceland cultures was only slightly lower than in the metal-free cultures. The SRB fraction of Furnas A2 was more susceptible to metals, and recovery was 2 orders of magnitude higher in the metal-free cultures. Total bacterial cell growth was less influenced by metals in all mixed cultures; in the Iceland cultures, the final bacterial concentrations were similar in the metal-amended and the metal-free cultures (Figure 2d), whereas in Furnas A2 and Mines the total concentrations decreased by approximately 1 order of magnitude. Total bacteria in the Furnas samples were reduced by 2 orders of magnitude in the presence of metals.

Identification of Key Players in Metal Resistant SRB Communities. The majority of the 16S rRNA gene fragments analyzed were assigned to two main taxa (SI Figure S2): the Gram-negative phylum Proteobacteria (especially of the Delta class, genus Desulfovibrio, and of the Gamma class) and the Gram-positive genus Clostridium, order Clostridiales, of the Firmicutes phylum. Two subpopulations within the sequences classified as Desulfovibrio were found, hereafter denoted Desulfovibrio group I and group II. Desulfovibrio group I (present in all samples) was closely related to $D$. desulfuricans (100\% gene similarity with type strain Essex 6, accession number AF192153) while Desulfovibrio group II (present in the metal-sensitive Furnas cultures) was closely affiliated to $D$. vulgaris (100\% gene similarity with type strain DSM 644, accession no. AF418179). Nucleotide sequences assigned to the Gammaproteobacteria were taxonomically more heterogeneous, diverging at the order level. Four sequences were assigned to the Oceanospirillales, 1 to Pseudomonas sp., 2 to Altermonadaceae and two classified as unknown Gammaproteobacteria. Clostridium spp. were found exclusively in the metal-resistant Iceland and Furnas A2 cultures and were assigned to two major clusters: Clostridium cluster XI (family Peptostreptococcaceae) and Clostridium sensu stricto (cluster I, family Clostridiaceae). Sequences assigned to Clostridium cluster I were closely affiliated to C. butyricum, C. subterminale, C. beijerinckii, and C. sulfidigenes. Sequences assigned to Clostridium cluster XI were closely affiliated to C. bifermentans (SI Figure S3). All sequences obtained for spore-forming Gram-positive bacteria were phylogenetically distant from the sulfate reducing Desulfotomaculum spp., Desulfosporosinus spp., and Desulfonispora sp. ${ }^{22}$ (SI Figure S3). Less abundant sequences present in Furnas A2, Iceland and Mines were assigned to Bacteroidetes (present in the Mines, Iceland and Furnas A2 cultures), Bacilli (in the Mines and Furnas A2 cultures) and Nocardioides sp. (one sequence in Mines).

Effect of Vancomycin on Metal Resistance. Vancomycin did not inhibit the SRB in the metal-free cultures; sulfate consumption was similar with or without vancomycin (Figure $3)$. In the metal-amended cultures, however, vancomycin

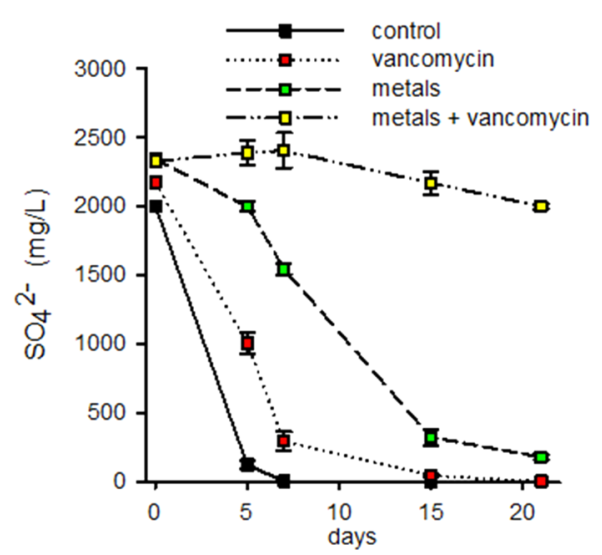

Figure 3. Influence of vancomycin $(10 \mu \mathrm{g} / \mathrm{mL}$ daily $)$ on the sulfate reduction capacity of the metal-resistant mixed SRB cultures. Values are means of four replicates. Error bars indicate standard deviation.

strongly inhibited sulfate reduction, while sulfate reduction activity was maintained in the cultures incubated only with metals. Hence, although not directly affected by vancomycin, Desulfovibrio sp. was only able to reduce sulfate in the presence of metals if the Gram-positive component of the culture was not inactivated by the addition of vancomycin.

Isolation of the Clostridia from Mixed SRB Cultures. Spore-forming clostridia were isolated from the SRB as demonstrated by DNA fingerprinting, whereas in the mixed Iceland and Furnas cultures a strong band $(2 \mathrm{~kb})$ was obtained with the primers targeting the $d s r a b$ gene (SI Figure S4a, lanes 4-5 in). No product could be detected with the same primers and the same amount of DNA in the same cultures after the heating and inoculation cycles (lanes 1-2). This indicated that, first, SRB had been out selected and, second, the members of the isolated spore-forming subculture did not display the $d s r a b$ gene as would be the case of Gram-positive sulfate reducing bacteria. ${ }^{22}$ Sulfate was consumed neither in the metal-free nor in the metal-amended Clostridium-enriched cultures for 21 days, providing additional evidence for the successful separation of Clostridium spp. from Desulfovibrio spp. (SI Figure S4b). Partial sequencing of the $16 \mathrm{~S}$ rRNA gene supplied additional evidence that Clostridium spp. had been separated from Desulfovibrio spp. (SI Table S2). Finally, aerobic bacteria (e.g., Bacilli) ${ }^{22}$ were not present in the isolated cultures, as demonstrated by the lack of growth of concentrated suspensions of the clostridial cultures 

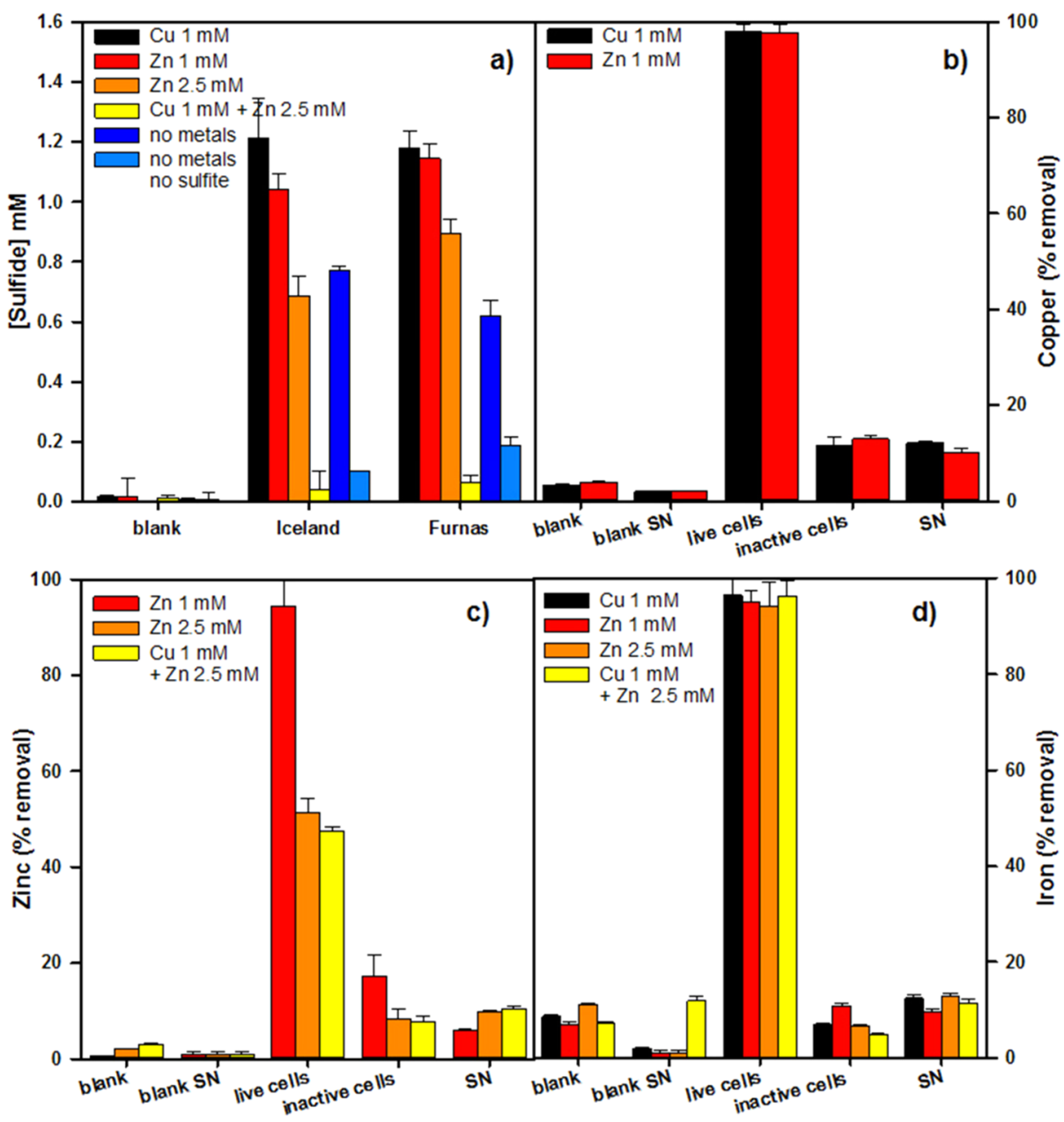

Figure 4. Sulfide production (a) and copper (b), zinc (c) and iron (d) removal after 7 days by different fractions of the clostridia cultures: live cells, inactive (heat killed) cells and cell-free metabolites in the supernatant (SN). The supernatant was previously purged to remove sulfide. Metal concentrations in (b)-(d) are the average values determined for Iceland and Furnas A2. Three independent assays were carried out for each source in duplicate. Error bars indicate standard deviation.

on Postgate medium 2 supplemented with $15 \mathrm{~g} / \mathrm{L}$ agar on agar plates.

\section{Mechanism of Metal Removal by the Clostridia}

Cultures. Active clostridia cultures derived from Furnas A2 and Iceland were able to produce sulfide with similar efficiency (Figure 4a), precipitating the added metals with the formation of the typical black precipitates (Figures $4 b-d$ ). Therefore, pooled values are presented in Figure $4 b-d$. In the liquid phase of metal-free Iceland and Furnas subcultures, the amount of sulfide was $0.8 \mathrm{mM}$ and $0.6 \mathrm{mM}$, respectively. When sulfite was omitted from the Postgate medium 2, the amount of sulfide produced by the clostridia decreased to $0.10 \mathrm{mM}$ and $0.19 \mathrm{mM}$ in the Iceland and Furnas A2 subcultures, respectively, thus indicating that in these cultures most sulfide was formed from sulfite (sulfate was never consumed, SI Figure S4). In the Cuamended $(1.0 \mathrm{mM})$ clostridia live cell cultures, more sulfide $(1.2 \mathrm{mM})$ was present after 7 days than in the metal-free subcultures (Figure 4a) and almost all $\mathrm{Cu}$ (98.0\%) was removed (Figure $4 \mathrm{~b}$ ). At the same initial $\mathrm{Zn}$ concentration (1.0 $\mathrm{mM}$ ), $1.0 \mathrm{mM}$ sulfide was present (Figure $4 \mathrm{a}$ ) and $94 \% \mathrm{Zn}$ was removed (Figure 4c). At $2.5 \mathrm{mM} \mathrm{Zn}$, concentrations of sulfide in solution decreased compared to $1.0 \mathrm{mM} \mathrm{Zn}(0.7-0.9 \mathrm{mM}$; Figure $4 \mathrm{a}$ ) and only $51 \% \mathrm{Zn}$ was removed (Figure $4 \mathrm{c}$ ). When $\mathrm{Cu}$ and $\mathrm{Zn}$ were added together at $1.0 \mathrm{mM}$ and $2.5 \mathrm{mM}$, the amount of sulfide in solution strongly decreased (0.04-0.07 $\mathrm{mM}$; Figure $4 \mathrm{a})$ and a very similar $\mathrm{Cu}$ and $\mathrm{Zn}$ removal $(48 \%$ and $94 \%$, respectively) was measured indicating that $\mathrm{Cu}$ had little influence on $\mathrm{Zn}$ removal, and vice versa (Figure $4 \mathrm{~b}, \mathrm{c}$ ). Most iron present in the Postgate medium (1.5 mM, Figure $4 \mathrm{~d}$ ) was removed (94-96\%) in all clostridial cultures, regardless of the presence of other metals. Results in Figure 4 clearly show that within 7 days-a period equivalent to the initial phase in the mixed cultures with no sulfate reduction-living clostridial cells, while producing sulfide from sulfite, displayed a high metal bioremoval capacity in contrast to heat-killed cells or extracellular metabolites and removed the added $\mathrm{Cu}, \mathrm{Zn}$, and Fe to a similar extent as in the mixed SRB cultures in the same time. In the heat-killed subcultures, only limited amounts of metal were removed $(12-13 \%$ for copper, $8-17 \%$ for zinc and $7-11 \%$ for iron, Figures $4 \mathrm{~b}-\mathrm{d}$ ), indicating that metal removal by clostridia is metabolism-dependent. After purging the dissolved sulfide from the medium, the cell-free supernatant metabolites only removed residual amounts of copper (10$12 \%)$, zinc $(6-10 \%)$, and iron (9-13\%, Figure $4 b-d)$.

\section{DISCUSSION}

We have established clostridia as key elements in conferring metal resistance to sulfidogenic cultures based on Desulfovibrio 
spp., which otherwise display no activity in the presence of high $\mathrm{Cu}(\mathrm{II}), \mathrm{Zn}(\mathrm{II})$, and $\mathrm{Fe}(\mathrm{II})$ concentrations. To the best of our knowledge, this is the first time that the decisive role of clostridia in initiating $\mathrm{Cu}, \mathrm{Fe}$, and $\mathrm{Zn}$ bioremoval in mixed SRB cultures has been demonstrated.

It is generally accepted that SRB protect themselves against toxic metals through the generation of sulfide, with the concomitant precipitation of the metals as metal sulfides. ${ }^{5}$ In its turn, sulfide is also toxic to SRB cells by reacting with metal ions and functional groups of electro carrier systems in the cells. ${ }^{23}$ Additionally, sulfide can form a coating on the surface of SRB, thereby blocking access to nutrients. ${ }^{6}$ Hence the removal of soluble sulfide by binding to metals is also beneficial to SRB, especially at low $\mathrm{pH}^{23,24}$

While sulfide production by Desulfovibrio spp. in the mixed SRB cultures was inhibited by the high concentrations of the metals added, the closely related Desulfovibrio spp. populations in the Iceland and Furnas A2 cultures (with Clostridium spp.) could resume sulfate reduction under the same conditions. Of the three metals tested, zinc and-especially-copper are toxic to SRB, and have an EC100 (the lowest effective concentration at which no sulfate reduction takes place) of $0.19 \mathrm{mM}$ for copper and $0.31 \mathrm{mM}$ for zinc in mixed sulfidogenic cultures. ${ }^{6,11}$ But in the Iceland and Furnas A2 mixed SRB cultures, sulfate and lactate were depleted in the presence of considerably higher concentrations of the same metals. Since all detected SRBs were closely affiliated $(99 \%-100 \%)$ to $D$. desulfuricans and D. vulgaris, and the concentrations of their active, culturable fraction were similar for the metal-sensitive and resistant cultures, it is likely that the reason for the different responses of the SRB populations to the heavy metals was due to associated bacteria in the metal-resistant cultures. It cannot be ruled out that other, undetected SRBs were present in the resistant cultures, or that the effective concentrations of SRB were different from those obtained by cultivation cannot be ruled out. Nevertheless, it seems unlikely that a bacterial fraction not detected by universal $16 \mathrm{~S}$ rRNA analysis and unable to thrive in the culture medium was responsible for the striking physiologic differences between the sensitive and the resistant cultures.

The most evident feature exclusive to all metal-resistant cultures was a high fraction of spore-forming, Gram-positive bacteria belonging to the Clostridiaceae family, most of them closely affiliated to the genus Clostridium clusters I and XI. When Clostridium spp. were present, significant metabolic activity and concomitant metal removal were detected in the first week of incubation in the metal-resistant cultures. During this time, no sulfate reducing activity was detected. By inhibiting the Clostridium spp. with vancomycin, the metalresistant cultures became metal-sensitive and metabolic activity stopped. Thus, the data clearly indicate that Clostridium spp. initiated metabolic activity and metal removal during the first week after metal addition, i.e., prior to the SRB, which were only active at lower metal concentrations.

The physiological assays carried out with isolated Clostridium spp. clearly demonstrate that these populations can have metabolic activity in the presence of the concentrations of copper and zinc used in the mixed cultures. Fe was not tested separately because it is much less toxic than $\mathrm{Cu}$ and $\mathrm{Zn}$. Furthermore, the Clostridium-mediated $\mathrm{Cu}$ and $\mathrm{Zn}$ removal during the first week was similar to the extent of $\mathrm{Cu}$ and $\mathrm{Zn}$ removal during the same period of activity of the mixed SRB cultures. Metal removal measurements on active cultures and heat-killed clostridial cells indicated that the main metal decontamination mechanism required active cells, in agreement with the vancomycin results. The small reduction in metal concentration in the heat-killed bacteria suggests a minimal contribution of metabolically passive processes, such as adsorption of the metals to the bacterial cell walls (biosorption). ${ }^{25}$ Likewise, as the data obtained with the culture supernatants show, extracellular metabolites also did not play a significant role in copper and zinc bioremoval.

Sulfide and sulfate measurements performed in the metalamended and metal-free cultures have shown that sulfide production by Clostridium spp. was carried out mainly by the reduction of sulfite, but not sulfate. The reference strains most closely related to the isolates ( $C$. butyricum, C. subterminale, $C$. bifermentans, and $C$. beijerinckii) are described as sulfite reducers. $^{26-28}$ In Clostridium spp., sulfite is reduced by an inducible dissimilatory sulfite-reductase of the asrC type. ${ }^{29,30}$ The active centers of these enzymes contain a siroheme covalently coupled to an iron sulfur cluster $\left(\mathrm{Fe}_{4} \mathrm{~S}_{4}\right)$. Both form a metallo-cofactor by means of which electrons are delivered to the acceptor substrate. ${ }^{31}$ Sulfide reductase was probably induced by metal addition, which would explain the higher level of sulfide production in the metal-amended Clostridium spp. cultures as compared to the metal-free controls. Other possible sulfide sources, besides sulfite, which could have accounted for the low sulfide generation $(0.1-0.2 \mathrm{mM})$ detected in the sulfite-free media are yeast extract ${ }^{32,33}(2 \mathrm{~g} / \mathrm{L})$ and possibly thiosulfate ${ }^{32}$ derived from partial reduction of low amounts of sulfate.

In the cultures incubated with $1.0 \mathrm{mM}$ copper and $1.5 \mathrm{mM}$ iron or $1 \mathrm{mM}$ zinc and $1.5 \mathrm{mM}$ iron, all metals were removed from solution. However, if zinc was added at $2.5 \mathrm{mM}$ start concentrations, then approximately $1 \mathrm{mM}$ of zinc was detected in solution after incubation. Since sulfide was present in solution $(0.7-0.9 \mathrm{mM})$, and the solubility constant of $\mathrm{ZnS}$ is low $\left(1 \times 10^{-29}\right){ }^{4}$ some factor must have prevented zinc from precipitating. A possible explanation could be the $\mathrm{pH}$; it increased from 5.9 to 6.3-6.6 during incubation (data not shown) but possibly not enough to enable complete zinc precipitation, since $\mathrm{ZnS}$ complexes have been reported to dissociate below $\mathrm{pH} 6.7$ and release sulfide. ${ }^{34}$ Lower zinc removal efficiency was also measured in the course of this study for the mixed SRB cultures in comparison to that of iron and copper.

Besides initiating the metal bioremediation process by removing considerable amounts of copper, zinc, and iron, Clostridium spp. may have had additional enhancing effects on the activity of the SRB populations. The initial redox potential of the culture medium increased to $50-60 \mathrm{mV}$ due to heavy metal addition, while the $\mathrm{pH}$ decreased to 5.3. Although both initial values are not favorable to mesophilic SRB, ${ }^{19}$ they were not altered in order to select for consortia with more potential of performing metal bioremediation under conditions similar to those in AMD. Hence, Clostridium spp. may have also been crucial for the onset of sulfate reduction by raising the initial $\mathrm{pH}$ and decreasing the redox potential.

Syntrophy between SRB and Clostridium sp. has been described $^{35,36}$ in which Clostridium spp. fermented complex substrates, and provided Desulfovibrio spp. with simple carbon sources.' Although in the mixed cultures, Clostridium spp. may have provided Desulfovibrio spp. with fermentation products derived from yeast extract, ${ }^{22,33}$ this interaction was probably not primarily relevant for the high performance of the culture, since lactate-a preferred substrate to Desulfovibrio spp. ${ }^{19}$ - was 
abundant in the medium. Another frequent fermentation product of clostridia is $\mathrm{H}_{2}$ and interspecies hydrogen transfer has been described between fermentative bacteria and SRB. ${ }^{19}$ C. butyricum, C. bifermentans, and C. subterminale, to which several members of the Iceland and Furnas A2 cultures are closely affiliated, produce abundant $\mathrm{H}_{2}{ }^{33}$ Indeed, $\mathrm{H}_{2}$ may promote higher sulfide production by $\mathrm{SRB},{ }^{37}$ as well as the growth of a greater variety of SRB. ${ }^{22}$ Clostridium-driven metal precipitation with concomitant $\mathrm{pH}$ increase, decrease of redox potential, and metabolite production probably created highly favorable conditions for the onset of Desulfovibrio spp. activity. These benefits may explain why the decontamination process carried out by these cultures is faster than other systems. ${ }^{13}$ The positive action of Clostridium spp. in initiating metal removal and $\mathrm{pH}$ increase may eventually be obviated if more metaltolerant, pH-resistant SRB (e.g., Desulfosporosinus spp. and Desulfitobacterium spp. $)^{14,38}$ are used for heavy metal removal. This association could be of interest for bioremediation technologies.

While Clostridium spp. played a crucial role in initiating metal bioremoval in the mixed cultures, they could have some limitations if they were to carry out bioremediation alone: low sulfite concentrations in AMD would limit the extent of sulfide production and $\mathrm{pH}$ increase. SRB complete the action of Clostridium spp. by consuming the abundant sulfate present in $A M D$ and generating sulfide and significantly raising the environmental $\mathrm{pH}$. Hence, the evidence for a major enhancing effect of a Clostridium spp.-Desulfovibrio spp. association in metal bioremoval underlines the importance to explore the potential of Clostridia as biocatalysts for attenuation of heavy metal toxicity. The observations made in this study also provide general insights into how concerted action in bacterial consortia leads to successful colonization of inhospitable environments.

\section{ASSOCIATED CONTENT}

\section{S Supporting Information}

Locations and metal composition of the soil sources (Table $\mathrm{S} 1$ ); PCR-DGGE (Figure S1) and band sequencing procedures; phylogeny of $16 \mathrm{~S}$ rRNA gene sequences of the mixed sulfidogenic cultures (Figure S2); detailed phylogeny of the clostridial populations (Figure S3); isolation of members of the Clostridia from SRB (Figure S4); and phylogeny of 16S rRNA gene sequences obtained from isolated clostridial cultures (Table S2). This material is available free of charge via the Internet at http://pubs.acs.org.

\section{AUTHOR INFORMATION}

\section{Corresponding Author}

*Phone: + 351 (0) 289800900 ext. 7336; fax: +351-280800051; e-mail: mfernandes@ualg.pt.

\section{Notes}

The authors declare no competing financial interest.

\section{ACKNOWLEDGMENTS}

This research was funded by the National Foundation for Science and Technology (FTC), Portugal, through the annual budget of the Environmental Technologies group of CCMAR and project PEst-C/MAR/LA0015/2011. M.A. received fellowship BPD46603/2008 from FCT.

\section{REFERENCES}

(1) Johnson, D. B.; Hallberg, K. B. Acid mine drainage remediation options: A review. Sci. Total Environ. 2005, 338 (1-2), 3-14.

(2) Neculita, C. M.; Zagury, G. J.; Bussiere, B. Passive treatment of acid mine drainage in bioreactors using sulfate-reducing bacteria: Critical review and research needs. J. Environ. Qual. 2007, 36 (1), 116.

(3) Mudd, G. M.; Patterson, J. Continuing pollution from the Rum Jungle U-Cu project: A critical evaluation of environmental monitoring and rehabilitation. Environ. Pollut. 2010, 158 (5), 1252-1260.

(4) Sheoran, A. S.; Sheoran, V.; Choudhary, R. P. Bioremediation of acid-rock drainage by sulphate-reducing prokaryotes: A review. Miner. Eng. 2010, 23 (14), 1073-1100.

(5) Cabrera, G.; Perez, R.; Gomez, J. M.; Abalos, A.; Cantero, D. Toxic effects of dissolved heavy metals on Desulfovibrio vulgaris and Desulfovibrio sp. strains. J. Hazardous. Mater. 2006, 135 (1-3), 40-46.

(6) Utgikar, V. P.; Chen, B. Y.; Chaudhary, N.; Tabak, H. H.; Haines, J. R.; Govind, R. Acute toxicity of heavy metals to acetate-utilizing mixed cultures of sulfate-reducing bacteria: EC100 and EC50. Environ. Toxicol. Chem. 2001, 20 (12), 2662-2669.

(7) Valls, M.; de Lorenzo, V. Exploiting the genetic and biochemical capacities of bacteria for the remediation of heavy metal pollution. FEMS Microbiol. Rev. 2002, 26 (4), 327-338.

(8) White, C.; Gadd, G. M. Accumulation and effects of cadmium on sulphate-reducing bacterial biofilms. Microbiol.-UK 1998, 144, 14071415.

(9) Castillo, J.; Perez-Lopez, R.; Sarmiento, A. M.; Nieto, J. M. Evaluation of organic substrates to enhance the sulfate-reducing activity in phosphogypsum. Sci. Total Environ. 2012, 439, 106-113.

(10) Hsu, H. F.; Jhuo, Y. S.; Kumar, M.; Ma, Y. S.; Lin, J. G. Simultaneous sulfate reduction and copper removal by a PVAimmobilized sulfate reducing bacterial culture. Bioresour. Technol. 2010, 101 (12), 4354-4361.

(11) Jin, S.; Drever, J. I.; Colberg, P. J. S. Effects of copper on sulfate reduction in bacterial consortia enriched from metal-contaminated and uncontaminated sediments. Environ. Toxicol. Chem. 2007, 26 (2), 225-230.

(12) Pagnanelli, F.; Cruz Viggi, C.; Cibati, A.; Uccelletti, D.; Toro, L.; Palleschi, C. Biotreatment of $\mathrm{Cr}(\mathrm{VI})$ contaminated waters by sulphate reducing bacteria fed with ethanol. J. Hazard. Mater. 2012, 199, 186192.

(13) Alexandrino, M.; Macias, F.; Costa, R.; Gomes, N. C. M.; Canario, A. V. M; Costa, M. C. A bacterial consortium isolated from an Icelandic fumarole displays exceptionally high levels of sulfate reduction and metals resistance. J. Hazard. Mater. 2011, 187 (1-3), 362-370.

(14) Sanchez-Andrea, I.; Stams, A. J. M.; Amils, R.; Luis Sanz, J. Enrichment and isolation of acidophilic sulfate-reducing bacteria from Tinto River sediments. Environ. Microbiol. Rep. 2013, 5 (5), 672-678.

(15) Postgate, J. R. The Sulphate-Reducing Bacteria, $2^{\text {nd }}$ ed.; Cambridge University press: Cambridge, 19884; p 208.

(16) Rothe, O.; Thomm, M. A simplified method for the cultivation of extreme anaerobic Archaea based on the use of sodium sulfite as reducing agent. Extremophiles 2000, 4 (4), 247-252.

(17) Watanakunakorn, C. Mode of action and in-vitro activity of vancomycin. J. Antimicrob. Chemother. 1984, 14 (suppl.D), 7-18.

(18) Goldstein, E. J. C.; Citron, D. M.; Merriam, C. V.; Warren, Y. A.; Tyrrell, K. L.; Fernandez, H. T. In vitro activities of the new semisynthetic glycopeptide telavancin (TD-6424), vancomycin, daptomycin, linezolid, and four comparator agents against anaerobic gram-positive species and Corynebacterium spp. Antimicrob. Agents Chemother. 2004, 48 (6), 2149-2152.

(19) Madigan, M. T.; Martinko, J. M.; Stahl, D. A.; Clark, D. P. Brock Biology of Microorganisms, $13^{\text {th }}$ ed.; Benjamin Cummings: San Francisco, 2012.

(20) Wagner, M.; Roger, A. J.; Flax, J. L.; Brusseau, G. A.; Stahl, D. A. Phylogeny of dissimilatory sulfite reductases supports an early origin of sulfate respiration. J. Bacteriol. 1998, 180 (11), 2975-2982. 
(21) Teske, A.; Hinrichs, K. U.; Edgcomb, V.; Gomez, A. D.; Kysela, D.; Sylva, S. P.; Sogin, M. L.; Jannasch, H. W. Microbial diversity of hydrothermal sediments in the Guaymas Basin: Evidence for anaerobic methanotrophic communities. Appl. Environ. Microbiol. 2002, 68 (4), 1994-2007.

(22) Vos, P. G. G.; Jones, D.; Krieg, N. R.; Ludwig, W.; Rainey, F. A.; Schleifer, K.-H.; Whitman, W. B., Eds.; Bergeýs Manual of Systematic Bacteriology, $2^{\text {nd }}$ ed.; Williams \& Wilkins: Baltimore, MD, 2009; Vol. 3: The Firmicutes.

(23) Koschorreck, M. Microbial sulphate reduction at a low $\mathrm{pH}$ microbial sulphate reduction at a low $\mathrm{pH}$. FEMS Microbiol. Ecol. 2008, 64 (3), 329-342.

(24) Holmer, M.; Storkholm, P. Sulphate reduction and sulphur cycling in lake sediments: A review. Freshwater Biol. 2001, 46 (4), 431-451.

(25) Chojnacka, K. Biosorption and bioaccumulation-The prospects for practical applications. Environ. Int. 2010, 36 (3), 299-307.

(26) Ghoddusi, H. B.; Sherburn, R. Preliminary study on the isolation of Clostridium butyricum strains from natural sources in the UK and screening the isolates for presence of the type $\mathrm{E}$ botulinal toxin gene. Int. J. Food Microbiol. 2010, 142 (1-2), 202-206.

(27) Adcock, P. W.; Saint, C. P. Rapid confirmation of Clostridium perfringens by using chromogenic and fluorogenic substrates. Appl. Environ. Microbiol. 2001, 67 (9), 4382-4384.

(28) Prevost, S.; Cayol, J.-L.; Zuber, F.; Tholozan, J.-L.; Remize, F. Characterization of clostridial species and sulfite-reducing anaerobes isolated from foie gras with respect to microbial quality and safety. Food Control 2013, 32 (1), 222-227.

(29) Laishley, E. J.; Lin, P. M.; Peck, H. D. Ferredoxin-linked sulfite reductase from Clostridium pasteurianum. Can. J. Microbiol. 1971, 17 (7), 889-\&.

(30) Harrison, G.; Curle, C.; Laishley, E. J. Purification and characterization of an inducible dissimilatory type sulfite redcutase from Clostridium pasteurianum. Arch. Microbiol. 1984, 138 (1), 72-78.

(31) Dhillon, A.; Goswami, S.; Riley, M.; Teske, A.; Sogin, M. Domain evolution and functional diversification of sulfite reductases. Astrobiology 2005, 5 (1), 18-29.

(32) Sallam, A.; Steinbuechel, A. Clostridium sulfidigenes sp. nov., a mesophilic, proteolytic, thiosulfate- and sulfur-reducing bacterium isolated from pond sediment. Int. J. Syst. Evol. Microbiol. 2009, 59, 1661-1665.

(33) www.dsmz.de.

(34) Luther, G. W.; Rickard, D. T.; Theberge, S.; Olroyd, A. Determination of metal (Bi)Sulfide stability constants of $\mathrm{Mn}^{2+}, \mathrm{Fe}^{2+}$, $\mathrm{Co}^{2+}, \mathrm{Ni}^{2+}, \mathrm{Cu}^{2+}$, and $\mathrm{Zn}^{2+}$ by voltammetric methods. Environ. Sci. Technol. 1996, 30 (2), 671-679.

(35) Labrenz, M.; Banfield, J. F. Sulfate-reducing bacteria-dominated biofilms that precipitate $\mathrm{ZnS}$ in a subsurface circumneutral-pH mine drainage system. Microbial Ecol. 2004, 47 (3), 205-217.

(36) Miller, L. D.; Mosher, J. J.; Venkateswaran, A.; Yang, Z. K.; Palumbo, A. V.; Phelps, T. J.; Podar, M.; Schadt, C. W.; Keller, M. Establishment and metabolic analysis of a model microbial community for understanding trophic and electron accepting interactions of subsurface anaerobic environments. BMC Microbiol. 2010, 10, 149.

(37) Steger, J. L.; Vincent, C.; Ballard, J. D.; Krumholz, L. R. Desulfovibrio sp. genes involved in the respiration of sulfate during metabolism of hydrogen and lactate. Appl. Environ. Microbiol. 2002, 68 (4), 1932-1937.

(38) Dopson, M.; Johnson, D. B. Biodiversity, metabolism and applications of acidophilic sulfur-metabolizing microorganisms. Environ. Microbiol. 2012, 14 (10), 2620-2631. 